\title{
THE IMPACT OF THE OVERHEAD LINE'S POWER SUPPLY SYSTEM SPATIAL DIFFERENTIATION ON THE ENERGY CONSUMPTION OF TROLLEYBUS TRANSPORT: PLANNING AND ECONOMIC ASPECTS
}

\author{
Mikołaj Bartłomiejczyk ${ }^{1}$, Marcin Połom² \\ ${ }^{1}$ Dept of Electrical Transport, Gdansk University of Technology, Poland \\ ${ }^{2}$ Dept of Regional Development Geography, University of Gdansk, Poland
}

Submitted 3 February 2015; resubmitted 25 June 2015; accepted 9 July 2015; first published online 13 October 2015

\begin{abstract}
Nowadays the issue of electric energy saving in public transport is becoming a key area of interest, which is connected both with a growth in environmental awareness of the society and an increase in the prices of fuel and electricity. It can be achieved by reducing of the transmission losses in supply system or by the improving of the usage of the regenerative breaking. The spatial differentiation of the energy supply system of public transport is one of the elements, which has significant impact on the energy consumption. Paper presents the theoretical analysis of the impact of supply system topology on the energy consumption and extensive measurement analysis realized in Gdynia (Poland) trolleybus system.
\end{abstract}

Keywords: trolleybuses; energy recuperation; electric traction; Monte Carlo simulation; traction substation; energy savings; public transport; spatial differentiation.

\section{Introduction}

The development of zero-emission public transport is one of the elements of the horizontal EU policy. $\mathrm{Mu}-$ nicipal transport is currently responsible for $40 \%$ of $\mathrm{CO}_{2}$ emissions of the entire European road transport system. The transport sector is responsible for $30 \%$ of total energy consumption and $27 \%$ of greenhouse gas emissions. Greenhouse gas emissions must be reduced by $60 \%$ by 2050 (Falvo et al. 2011; Donno et al. 2012). What is more, the instability of the prices of liquid fuels has an extremely negative impact on the economy. Therefore, it is becoming necessary to use more alternative energy sources in public transport (Kühne 2010; Gunselmann 2005).

An alternative to liquid fuels is electricity. Today, we can notice the increase in the popularity of cars and electric buses powered by automotive batteries; however, the most effective way of providing electricity to vehicles is still a unipolar overhead line, as is the case for rail vehicles, or a bipolar line in the case of trolleybus service. Unfortunately, a large part of Europe's electricity is obtained from thermal power stations, which are also a source of greenhouse gas emissions. For this reason, the development of electric means of transport is actively supported by the European authorities, as evidenced e.g. by the funding of initiatives that popularize ecological municipal transport systems from the Community budget. One such project is Trolley, which was implemented in 2010-2013 and was aimed at popularizing trolleybus service and developing energy-saving technologies applied therein. A similar project is the Actuate project, which aims to highlight the importance of how driving techniques can affect the energy consumption of electric transport and it aims to implement the ecodriving concept. Currently, a group of selected European cities is implementing the Dyn@mo project, whose aim is to develop modern, energy-efficient technologies in public transport. A program directed solely at the technical aspect of energy efficiency of tram service is Osiris, which involves transport companies and manufacturers of commonly used electrical equipment for trams (Połom, Palmowski 2009; Połom, Bartłomiejczyk 2011).

\section{Energy Efficiency of Electric Municipal Transport}

One of the major advantages of electric traction is its lack of emission of atmospheric pollutants in the immediate vicinity, which is especially important under conditions of city traffic. However, a significant portion 
of the electricity is still produced in coal-fired thermal power stations and, therefore, the generation process is a source of air pollution. Therefore, an important issue related to reducing the emission of harmful gases into the atmosphere is to increase the energy efficiency of electric transport.

The total energy efficiency of electric transport consists of many factors, as shown in the diagrams in Fig. 1.

Each of the steps of the generation and conversion of electricity involves losses. These arise in the production of energy in power stations, during transmission to the public power grid, during the processing stage at the traction substations that supply the overheads line and in the overhead lines themselves. In addition, the electric motors in the vehicles are also inefficient. An important element affecting the overall efficiency of transport is the recuperation of electricity, which recovers of a part of the electricity during vehicle braking and allows for its re-use.

The efficiency of electricity generation and transmission systems is the subject of many scientific publications dealing with power systems (Scarpellini et al. 2013; Sweeting et al. 2011; White 1982). The energy efficiency of the drive unit is also the subject of numerous studies and considerable research (Skibicki, Judek 2009; Jarzebowicz 2014, 2011; Dolecek et al. 2012; Hrbac et al. 2014, 2013; García et al. 2013). It may be noted, that the efficiency of currently produced electric motors is close to the maximum from the technical point of view and further development of the motors will not substantially increase their efficiency. Similarly, the drive units used in currently manufactured electric vehicles have a high proportion of energy recovery during braking. Modern rectifier substations are equipped with highly efficient semiconductor rectifiers, so their impact on the overall efficiency of the power supply system is negligible.

The element that is the least frequently analysed in scientific research related to energy efficiency is the overhead lines and their supply system. The overhead lines generate losses during the supply of electricity from the traction substation to the vehicles. Moreover, the spatial structure of the power supply system has a major impact on the dispersed recuperation energy and is a key determinant of the extent of the utilization of the recouped energy. However, this fact is underestimated by experts who study the supply of municipal overhead lines. This results in power supply systems for tram and trolleybus lines that are designed and built without taking into account the need to minimize transmission losses in the line or increase the efficiency of recuperation. The impact of spatial conditions on energy is often downplayed. Most of the attention is given to the traction units or the energy efficiency in energy production and distribution in the public power grid. However, based on operational experience, transmission losses in the overhead lines can reach as high as $30 \%$, and a poorly designed power supply system can significantly reduce the use of recovered energy. Issues, such as the spatial structure of the power supply system, division of the overhead lines into sections and the manner of supplying the sections are crucial when minimizing the energy consumption of public transport. Among experts, the importance of the topology of the power supply system with respect to the effective use of recuperation is underestimated. Often, supercapacitor banks are presented as the only effective solution for the efficient use of energy from regenerative braking and its use by other vehicles is marginalized. The aim of this paper is to analyse the influence of the spatial structure of the power supply system on electricity consumption in municipal overhead lines to show the importance of the topology of the power supply system in terms of energy (Hamacek et al. 2014).

Chapters 2-4 show the effect of the spatial structure of the power supply system on energy consumption, while Chapter 5 presents the economic aspects of the construction of the power systems. A comparative analysis based on the calculations resulting from a simulation model of three power supply system options is presented in Chapter 6. Chapter 7 is devoted to studies measuring the effectiveness of regenerative braking. A trolleybus service system in Gdynia (Poland) was used for the conducting simulation and taking the measurements. Last chapter provides a summary and guidelines for the design, construction and modernization of power systems.

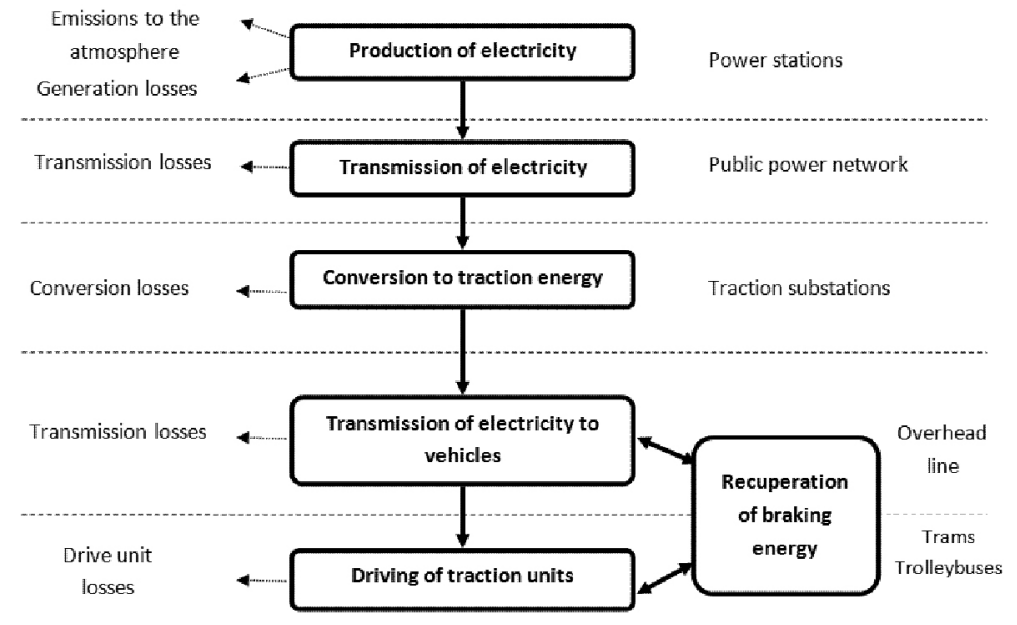

Fig. 1 . The electricity flow diagram and associated losses 


\section{The Structure of Power Supply Systems of Municipal Electric Traction}

Trams and trolleybuses are supplied with direct power from overhead lines. The energy used to supply the municipal overhead lines is drawn from the public HV AC grid and is converted to DC in traction substations, where voltage reduction occurs. After transformation and rectification, the energy from traction substations is supplied into power supply points of the overhead lines using power cables - known as feeders. For aesthetic reasons, feeders are mostly located underground. The overhead lines are divided into traction power supply sections so that it is possible to turn off a part of the line while maintaining supply to the remaining part.

From the spatial structure point of view, three different power systems for trams and trolleybuses may be distinguished (Figs 2-4):

- central power supply;

- unilateral decentralized power supply;

- bilateral decentralized power supply.

Central power supply originates from early electric municipal overhead lines, when the first tram systems were supplied from a single central power station (mostly steam, sometimes water stations). The development of public power systems contributed to the spread of traction substations supplied from the AC grid and converting it to DC, which was fed to the overhead lines. Traction substations, which were built until the 1960s, were equipped with mercury-arc rectifiers, which were associated with high construction costs and the need to ensure round-the-clock service. Therefore, the aim was to minimize the number of traction substations by maximizing their supply areas (Hamacek et al. 2014; Foiadelli et al. 2006; Iannuzzi et al. 2012; Barrero et al. 2008; Falvo, Foiadelli 2010).

A feature of a central power supply is the existence of large substations (supplying up to 20-40 feeders, which cover large areas of power supply, and supply points are sometimes located very far from the substation (Fig. 2). Feeders range up to $5 \mathrm{~km}$ in length, and their cross sections are up to $2000 \mathrm{~mm}^{2}$. Substations operating in a central system must provide an uninterruptible power supply, and hence they are powered by two lines from the grid and have at least two sets of rectifiers. Centrally-powered lines use unilateral power supply systems, i.e. each section of the power line is supplied from only one traction substation (Hamacek et al. 2014; Destraz et al. 2007).

The invention of semiconductor rectifiers and advent of prefabricated power stations contributed to the spread of small-sized traction substations (Fig. 3). As a result, the supply of overhead lines began to be decentralized. Under this system, substations are densely arranged (every $1-3 \mathrm{~km}$ ) and are located in the direct vicinity of overhead line supply points. Substations are equipped with one set (of 1-3 feeders), and in many cases, are fed only by one MV line. Damage to the rectifier set or a power line turns off the entire substation, therefore, stand-by power supply is provided by supply-

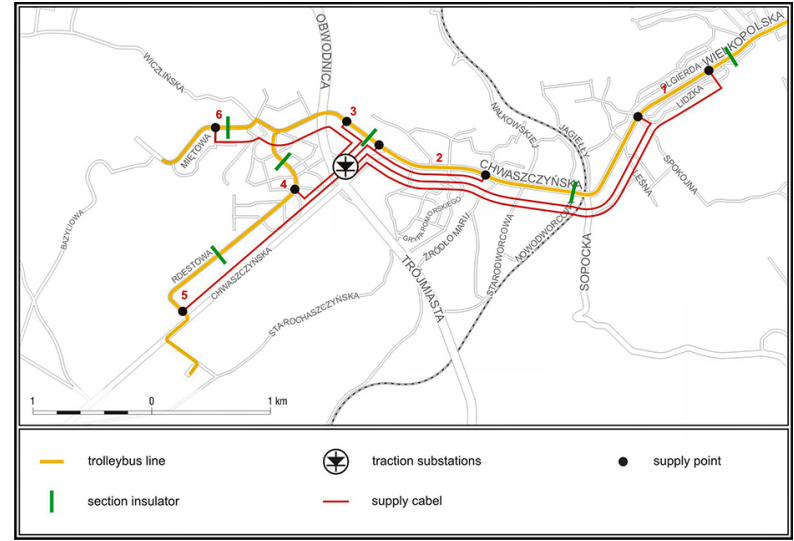

Fig. 2. Example of centralized supply system

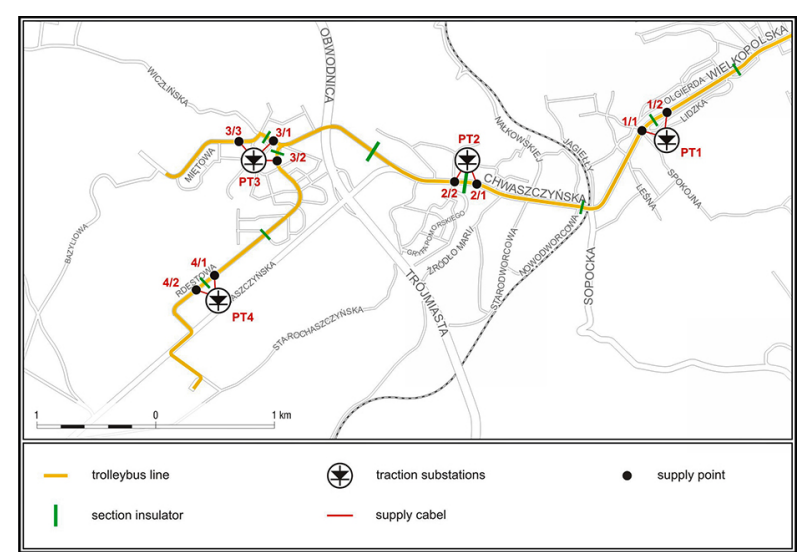

Fig. 3. Example of decentralized supply system, one-side supply

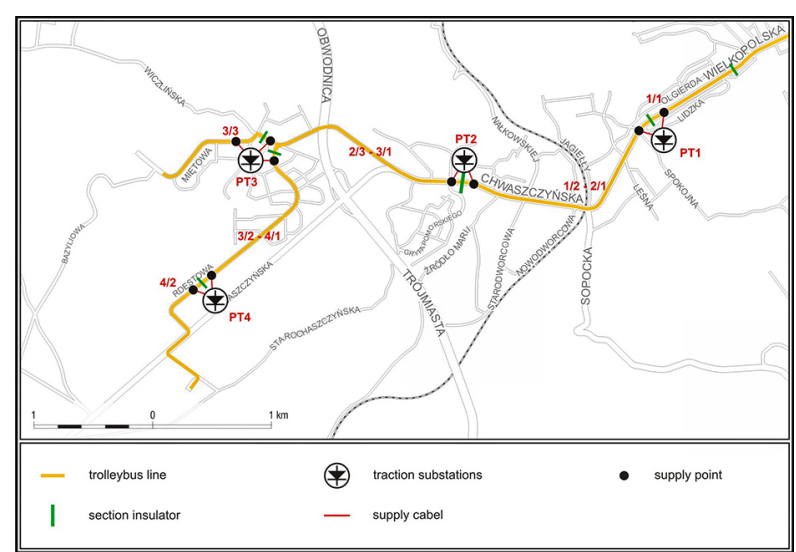

Fig. 4. Example of decentralized supply system, bilateral supply

ing electricity from neighbouring substations and combining the sections of the overhead lines.

In a classic supply system, every section of the overhead line is powered by a single substation. Technical progress in remote control engineering systems and protection technology has enabled the spread of twosided power supply systems for overhead lines (Fig. 4), wherein the sections of the line can be supplied by two or more different substations. This reduces the voltage drop in the overhead lines, and hence, reduces power 
transmission losses. Moreover, two-sided power supply allows for better energy recuperation (Hamacek et al. 2014).

A comparison of the three power supply systems for overhead lines shall be discussed later in this paper.

\section{Overhead Line Power Supply Systems vs. the Use of Recuperation Energy}

All electrical machines are able to work in two directions of energy flow. In the case of traction motors, this means the possibility of work as electric generator during braking of the vehicle, which involves converting the vehicle's kinetic energy into electrical energy, thereby producing the braking torque. This energy was at first dissipated in braking resistors located in the vehicle. The development of electric drive systems, especially high-power semiconductor drives, resulted in the spread of recuperation in trams and trolleybuses. It involves the recuperation of electric energy during braking of the vehicle, and its subsequent re-use.

Another important issue is to ensure the conditions that allow for the use of electricity generated during braking. In a classic supply system, where substations are not equipped with energy-storing devices, the flow of recuperative braking current may take place in two ways:

- in the following path: vehicle-overhead line-vehicle, when the braking vehicle and starting vehicle are in the same power supply section (Fig. 5);

- in the following path: vehicle-overhead linefeeder-busbars of the traction substation-feeder-overhead line-vehicle, when the vehicles are in two different power supply sections (Fig. 6).

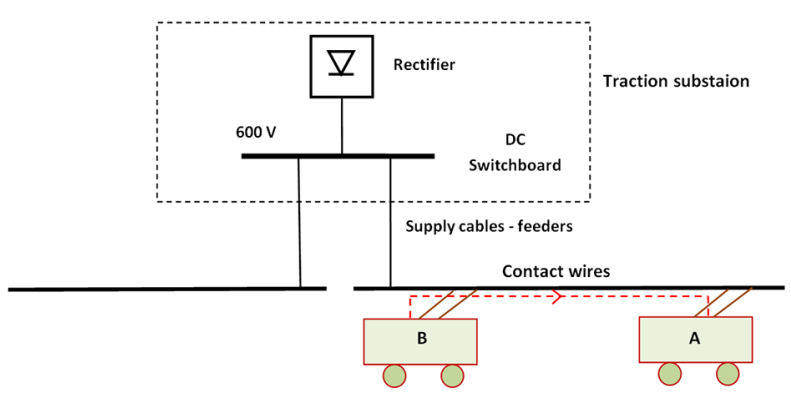

Fig. 5. Regenerative braking energy flow in case of vehicles on different power supply sections of the same traction substation

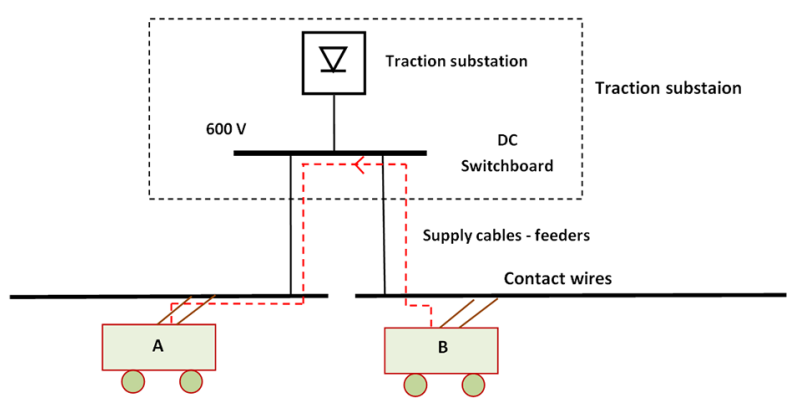

Fig. 6. Regenerative braking energy flow in case of vehicles on different power supply sections of the same traction substation
In both cases, the recouped energy is absorbed by the second vehicle in the power supply section, i.e. the vehicle is in motion. However, in common situations in the power supply areas, there are no vehicles present that are able to absorb the energy. When this happens, the recouped energy is dissipated in the braking resistors. The result is under-utilization of the potential for recuperation.

\section{The Importance of the Spatial Structure of the Supply System}

Based on Chapters 2-3, where the spatial structure of the overhead line power supply system affects two aspects of energy consumption:

- energy transmission losses in the overhead lines;

- the degree of utilization of regenerative braking.

Transmission losses are dependent on the resistance of the conductor, or the power cables and the overhead lines. This in turn depends on their length. Any increase in the distance between substations and hence increased length of the power cables increases transmission losses. Thus, transmission losses in a central power supply system for overhead lines (Fig. 2) in which it is necessary to provide energy to supply points far away from traction substations, are greater than in decentralized power supply systems (Fig. 3). A significant source of energy dissipation in a central supply system is the losses that occur in long power cables, whose length can be up to several kilometres. The issue of transmission losses is illustrated in Fig. 7. The red circle indicates the area of supply of a small substation, and the blue area marks the space supplied by a large substation. A larger supply area means greater distances between the substation and the vehicles. This example marks the location of two vehicles at distances $L_{1}$ and $L_{2}$ from the substation. The $L_{2}$ distance is greater than $L_{1}$, whereby the transmission losses will be greater in the second case. Thus, any increase in the size of the power supply area is associated with an increase in energy transmission losses.

The spatial structure of the supply system affects the efficiency of braking energy recovery. From the efficiency of recuperation point of view, it is important to ensure the largest possible number of potential consumers of recouped energy (other moving vehicles) and the possible paths of energy flow generated during braking, thus increasing the probability of finding a consumer for the recouped energy. This is illustrated in Fig. 8, with two possible substation power supply areas - the smaller one marked with a red circle, and the larger one with a blue circle. During braking (the braking vehicle is marked in green and with the letter $H$ ) in the case of the small power supply area (the red circle), the recouped energy can be absorbed by only 3 vehicles. Increasing the supply area (the blue circle) increases the number of potential consumers to 7 , which significantly increases the chance to use regenerative braking energy.

It can be argued that from the point of view of minimizing transmission losses, decentralized power supply systems in which the distances between the sub- 


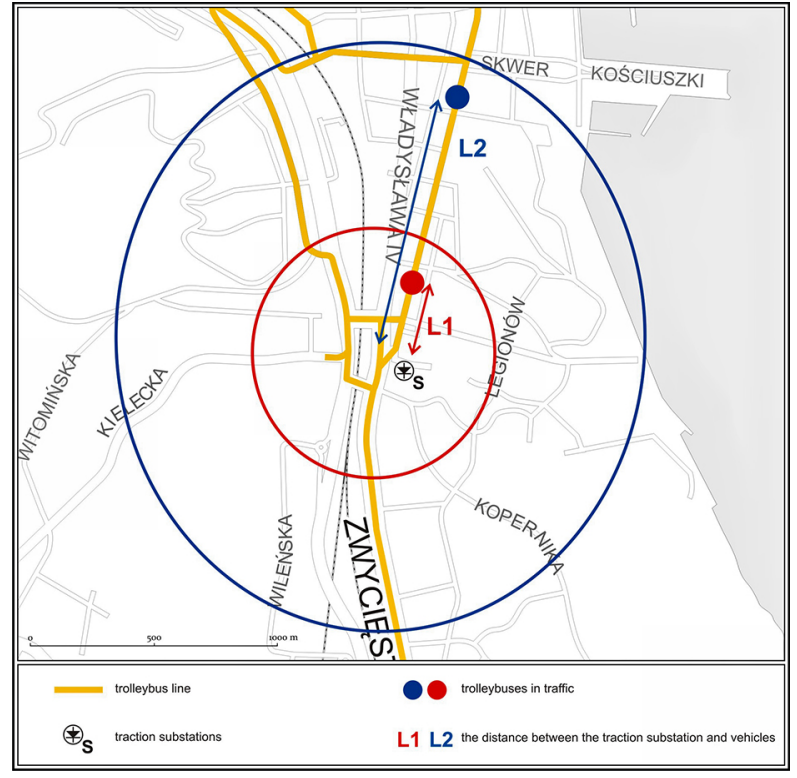

Fig. 7. An illustration of the effect of the size of the power supply area of the substation for electricity transmission losses - any increase in the size of the power supply area leads to an increase in the distances between the vehicles from the substation $\left(L_{1}>L_{2}\right)$, and consequently, an increase in transmission losses

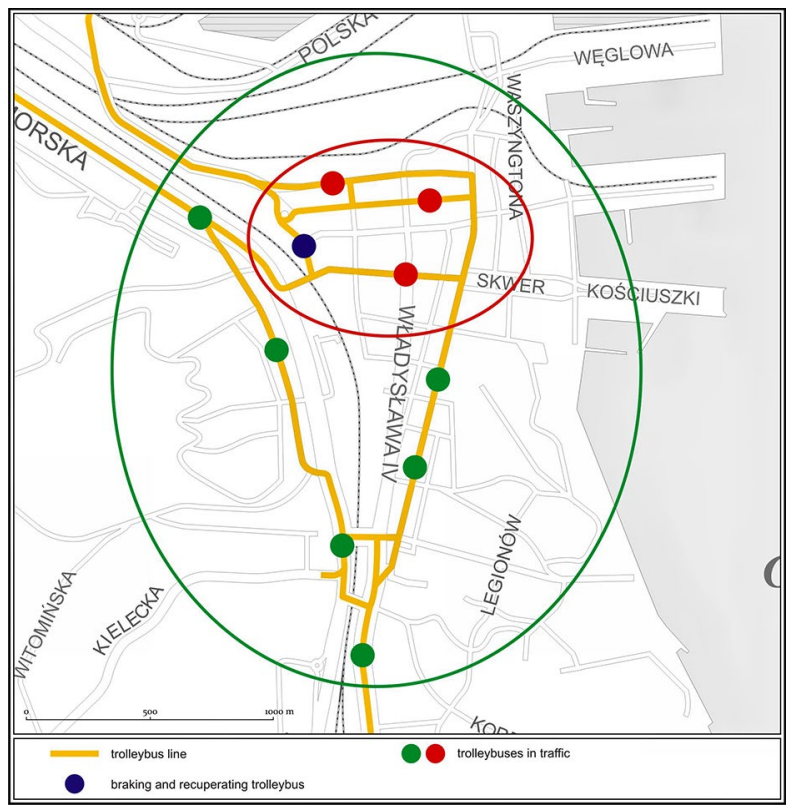

Fig. 8. An illustration of the effect of the size of the power supply area of the substation on electricity transmission losses - any increase in the size of the power supply increases the number of potential vehicles able to absorb the recouped energy

stations are smaller are preferable. Thus, the resulting energy transmission losses are smaller. On the other hand, the vast areas of power supply in central supply systems create much better conditions for the re-use of braking energy. One solution to overcome this contradiction, combining the advantages of a central and a decentralized power supply system with a unilateral power supply is to have bilateral supply for the overhead lines (Fig. 4). Due to the small distances between substations and the lengths of the power cables, energy transmission losses are low, while the connection of the supply areas of the individual substations enlarges the area where the recouped energy can flow and increases the number of potential consumers (Brenna et al. 2012a, 2012b; Diez et al. 2012; Pohl 2014; Gerndt, Stellmacher 1989).

\section{The Economic Aspects of the Spatial Structure of the Supply System}

The cost of construction of a power supply system includes:

- the cost of construction of traction substations;

- the cost of connecting the substation to the public power grid;

- the cost of construction of power cables.

Until the 1970s, traction substations were equipped with mercury-arc rectifiers, which was associated with significant construction costs and the need to ensure continuous service. For financial reasons, it was necessary to reduce the number of traction substations, which resulted in the popularization of central power supply systems.

The introduction of semiconductor rectifiers, the development of substation automation systems and modular container structures significantly reduced the cost of construction and operation of substations. With decentralized power supply systems, it is necessary to build a greater number of substations; however, due to the smaller distance between the substations, there is the possibility of redundancy of power between substations in the event of failure of one of them. With central power supply systems, there is no possibility of providing an emergency supply within the area of one of the substations from an adjacent one. Therefore, the requirements for the reliability of the substation in a decentralized supply system are less stringent than in the case of central systems, making it possible to simplify their design. This results in a reduction of construction costs. Similarly, with decentralized power supply systems, the cost of connection to the public power grid is lower. Due to their high reliability requirements, central substations must be supplied from at least two separate high-voltage power lines. The small-sized substations in decentralized supply systems allow for abandoning that requirement and for supplying the substation from only one line, thus reducing the construction costs of the power supply system.

An important cost component of supply system construction is the value of installation of feeders, including the value related to the occupation of plots and the difficulty of access in areas with high population density and massive underground infrastructure. Increases in prices of raw materials and the cost of construction means that for centralized systems, the cost of laying power cables may exceed the cost of construction of the substation. From this point of view, decentralized systems, in which the DC cable systems are minimized, are more advantageous. 
From the operational point of view, one disadvantage of centralized power systems is the cost associated with maintaining the extensive cable network. Feeders of municipal transport systems are located in dense urban areas, so they are exposed to damage during the later installation of new technologies and investments. What is more, due to the considerable degree of development in urban areas, the cost of removing damaged power cables is high. It should be noted that with decentralized power systems, the costs associated with the operation of cable networks are much lower. Table 1 shows a summary comparison of the advantages of both power supply systems for overhead lines. Under the present circumstances, from the economic point of view, the costs of construction and operation of decentralized systems are lower than that for central systems.

\section{A Comparative Analysis of Municipal Overhead Line Supply Systems}

Trams and trolleybuses are widespread means of transport in Europe. Different historical, technical and economic conditions in different countries have resulted in the existence of different solutions for public transport electric power systems. This is evident in the different structures of the power supply systems. A characteristic feature of the former Eastern Bloc countries (Poland, Czech Republic, Slovakia, countries of the former Soviet Union) is central power supply systems, while in Western Europe, the majority of tram and trolleybus services is powered in a decentralized manner. The spread of electricity banks is widely seen, but their use differs in different cities. For this reason, it is reasonable to make a comparative analysis of the different variants for supplying power to overhead lines.

A comparative analysis has been made using a fragment of the trolleybus service in Gdynia. The subject of the analysis is the supply area of the Chwaszczyniska traction substation. This substation is used to supply the hilly areas of the town, which promotes increased use of regenerative braking. Three different options of the power supply system are compared:

- option I: the supply area of the Chwaszczyniska substation (Fig. 2) in a central system;

- two hypothetical modifications to the power supply area that uses a decentralized system, in which power is supplied from four substations instead of one:
- option II: in a unilateral power supply system (Fig. 3);

- option III: in a bilateral power supply system

(Fig. 4).

Comparative studies were carried out by simulation analysis. The simulation of public transport supply system service was conducted using the Monte Carlo method (Hamacek et al. 2014).

The Monte Carlo method is based on the continuous repetition of a statistical experiment, which performs an analysis of the condition of the object using random input factors. The result is a distribution of probability of the output variable. The simulation model is based on the following input data:

- trolleybus timetables;

- deviations in the implementation of timetables that are designated using studies of punctuality of public transport conducted by Zarzad Komunikacji Miejskiej w Gdyni;

- trolleybus velocity profile - the relationship between the expected speed of vehicles and their location;

- traction characteristics of trolleybuses.

A histogram of the probability of the number of vehicles located within a power supply section at the same time was established using timetables and deviations from their implementation. The velocity profile, i.e. the relationship between the location of vehicle $s$ and its expected velocity $v(s)$ was the basis for determining the probability distribution of the location of individual vehicles along the power supply section. This probability $p(s)$ was inversely proportional to the expected velocity at a given location. The operating status of the drive unit and then the trolleybus current were determined using the derivative of the velocity profile. The currents and voltages in the power supply system were calculated iteratively using the node-voltage analysis until reaching the convergence of voltages $V$ in the calculation model. Fig. 9 provides a simplified diagram of the simulation model.

Using the Monte Carlo simulation method, the energy calculations of the power supply system of Chwaszczynska substation were calculated in the three presented options. The simulation was conducted using actual (as of May 2014) trolleybus timetables, so it was assumed that five lines with the following numbers were in service in the analysed area: $23,24,27,29$ and 31 . The

Table 1 . The advantages of central and decentralized power supply systems

\begin{tabular}{ll}
\hline \multicolumn{1}{c}{ Central system } & \multicolumn{1}{c}{ Decentralized system } \\
\hline - smaller number of objects in operation; & - lower costs of construction and operation of cable networks; \\
- the need to order less power from substations & - simpler construction of the substations; \\
than in a decentralized system, which translates & - no problems associated with maintaining extensive cable networks; \\
into lower electricity charges; however, this factor & - greater flexibility of the supply system, since the failure of a substation \\
depends on the individual manner of paying for & causes less turbulence than in the case of large' substations; \\
charges for ordering power. & $\begin{array}{l}\text { - easier design and construction process due to the significant unification } \\
\text { of the substations; } \\
\text { - easier to make repairs to the substations due to the possibility of } \\
\text { switching off one substation. }\end{array}$ \\
\hline
\end{tabular}


calculations also assumed that all trolleybus lines had Solaris Trollino 12 trolleybuses equipped with a drive system with an asynchronous $175 \mathrm{~kW}$ motor and having the technical capability to transfer regenerative braking energy to the overhead lines. The velocity profile was based on the current timetables and road speed limits. Table 2 shows a comparison of the energy and economic parameters of each of the three options for supplying power supply to the overhead lines. Fig. 10 presents the hourly electricity transmission losses in the overhead lines and the recovery of braking energy in the analysed supply area. In addition, the maximum potential for generating regenerative braking energy was indicated.

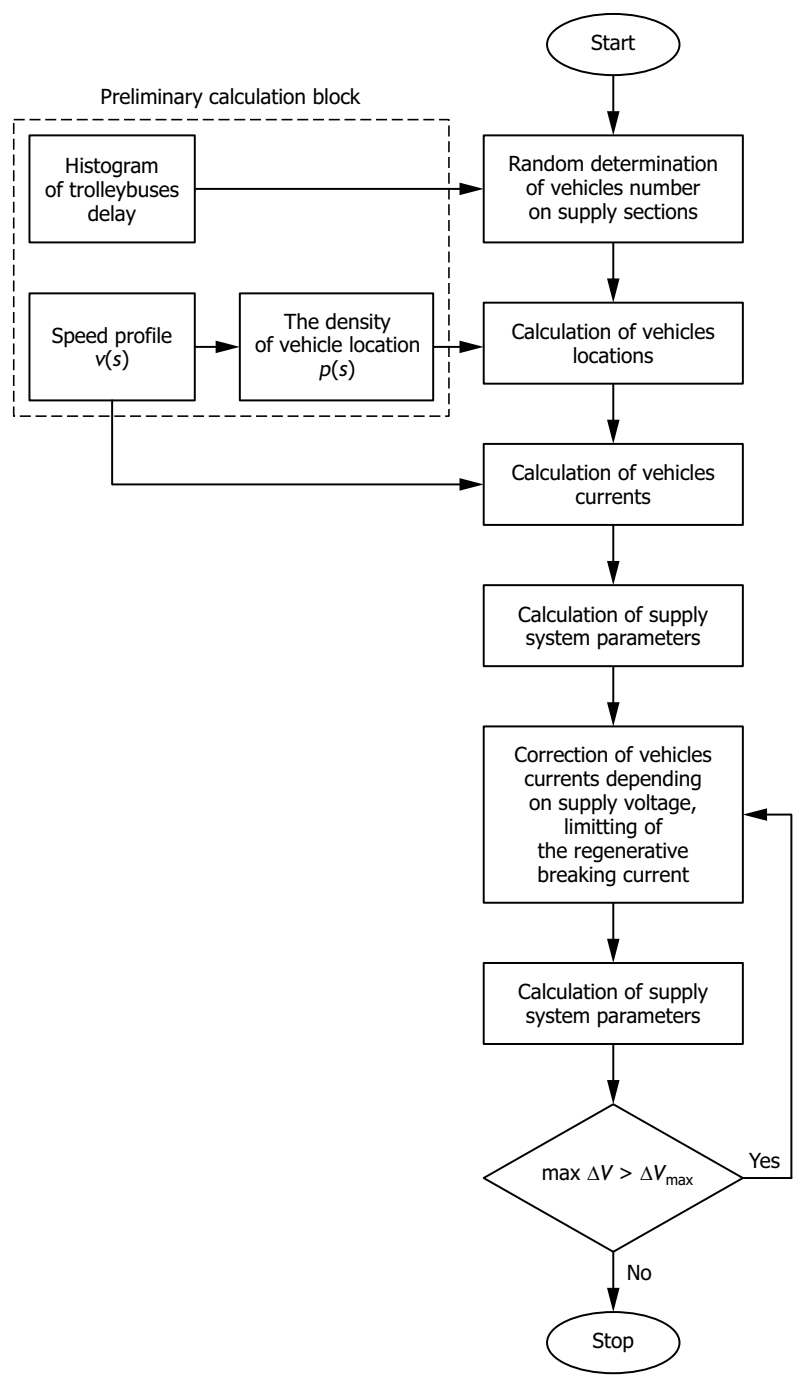

Fig. 9. General scheme of the traction power supply system simulation model using the Monte Carlo method

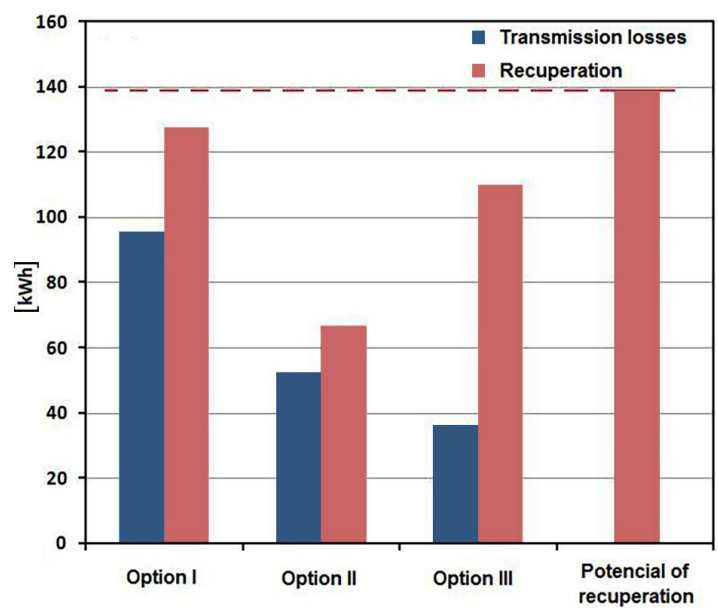

Fig. 10. Comparison of the breaking energy recuperation and transmission losses in analyzed options

The conducted simulation studies confirm the characteristics of the central and decentralized supply systems as specified in Chapters 2-4. Energy transmission losses in the supply network were much higher in the central system. Attention should be given to the nearly $30 \%$ figure in the central supply system (Table 2). However, these losses are compensated for by better use of energy recovery during braking (Fig. 10); resulting in the total energy consumption in option I being less than in option II. As expected, bilateral power supply combines the advantages of the centralized and decentralized systems. Transmission losses in option III are the lowest, while the utilization rate of recuperation is close to the central system. Fig. 10 also indicates the maximum obtainable braking energy recovery potential. It should be noted that the corresponding topology of the power supply system allows for using more than $80 \%$ of the energy generated during braking. Thus, in many cases, providing a distinguished spatial structure of the supply system can provide effective recuperation similar to the banks, with much lower investment costs.

Table 2 also shows a comparison of the estimated cost of construction of the power supply systems (of the substation and feeders). The calculations are based on the following economic assumptions (Połom, Palmowski 2009; Połom, Bartłomiejczyk 2011):

- the cost of construction of a substation for a central supply system: PLN 3 million;

- the cost of construction of a substation for a decentralized supply system: PLN 1 million;

- the costs of laying $1 \mathrm{~km}$ of a bipolar cable line: PLN 240 thousand.

Table 2. A comparison of the three options for trolleybus power supply

\begin{tabular}{cccccc}
\hline $\begin{array}{c}\text { Power supply } \\
\text { system option }\end{array}$ & $\begin{array}{c}\text { Total hourly energy } \\
\text { consumption [kWh] }\end{array}$ & $\begin{array}{c}\text { Recuperation } \\
\text { of braking } \\
\text { energy [\%] }\end{array}$ & $\begin{array}{c}\text { Use of the regenerative } \\
\text { braking potential [\%] }\end{array}$ & $\begin{array}{c}\text { Energy } \\
\text { transmission } \\
\text { losses [\%] }\end{array}$ & $\begin{array}{c}\text { Cost of construction } \\
\text { of the power supply } \\
\text { system [PLN million] }\end{array}$ \\
\hline Option I & 319 & 36 & 92 & 27 & 7.25 \\
\hline Option II & 361 & 18 & 48 & 14 & 5 \\
\hline Option III & 295 & 30 & 79 & 10 & 5 \\
\hline
\end{tabular}




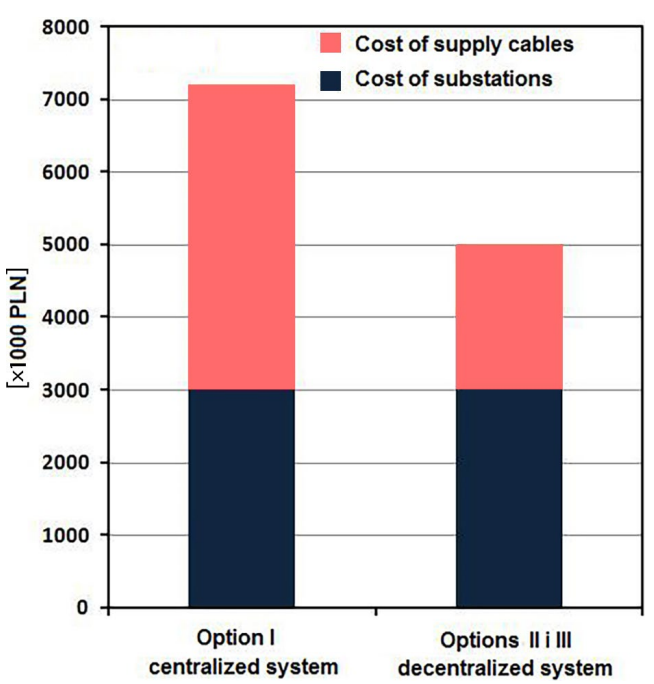

Fig. 11. Comparison of investments costs of supply options

Implementing option I requires the construction of one substation and laying $17.5 \mathrm{~km}$ of cable lines. For options II and III, it is required to construct four substations and lay $4.5 \mathrm{~km}$ of cable lines.

As expected, the costs for construction of decentralized systems are lower than central systems. A graphical comparison of the costs of construction of the supply system options, broken down into components, is shown in Fig. 11.

\section{Measuring the Recuperation Utilization Level}

During braking in diesel-engine traction units, the vehicle's kinetic energy is lost in mechanical brakes, converted into heat and dissipated. Therefore, it is irretrievably lost. In electric vehicles, thanks to recuperation, it is possible to convert the kinetic energy into electrical energy and re-use it.

Fig. 12 presents a diagram of the energy flow during the braking of an electric traction unit. During braking, the traction motor TM switches into genera-

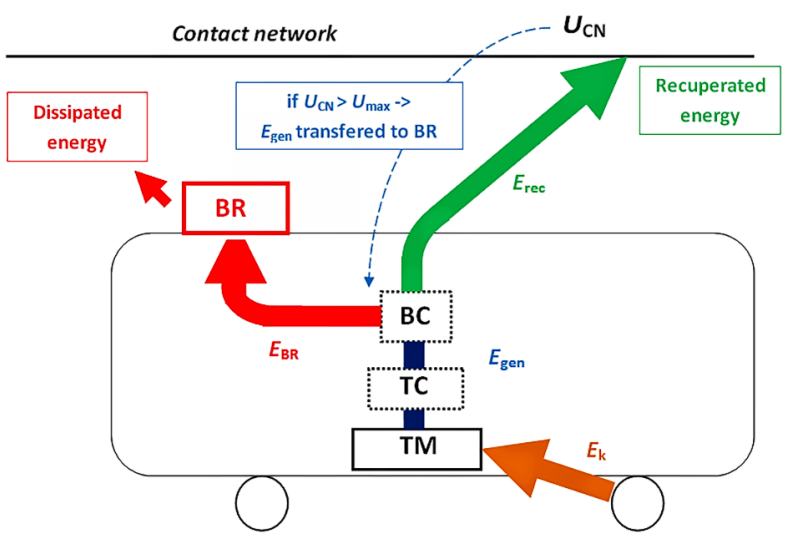

Fig. 12. Breaking energy low flow: $U_{C N}-$ voltage of contact supply network; $E_{k}-$ kinetic energy of vehicle; $E_{\text {gen }}$ - energy generated during breaking; $E_{\text {rec }}$ - energy recuperated to contact network; $E_{B R}$ - energy dissipated in breaking resistor;

$\mathrm{TM}$ - traction motor; TC - traction controller;

$\mathrm{BC}$ - breaking controller; $\mathrm{RH}$ - breaking resistor tor mode and a transformation of the kinetic energy $E_{k}$ of the vehicle into electrical energy takes place, which can then be returned to the overhead lines. However, in order to return electric energy into supply system it is necessary to generate voltage higher than it is in the overhead lines. For this purpose, during braking, the traction controller TC increases the voltage generated by the traction motor. First, the energy $E_{\text {gen }}$ generated in the drive unit by the braking inverter is directed into the overhead lines. In the absence of reception of the braking energy $E_{r e c}$, voltage in the overhead lines $U_{C N}$ on the vehicle's current collector exceeds the maximum recuperation voltage $U_{\max }$. This triggers the braking converter $\mathrm{BC}$, which directs the energy generated in the drive unit to the braking resistor. This energy is dissipated as heat. In networks with a rated voltage of $600 \mathrm{~V}$, the upper limit voltage $U_{\max }$ is assumed to be $770 \mathrm{~V}$. The worse the conditions for recuperation, i.e. there are no consumers in the overhead lines that can absorb the recuperation energy $E_{r e c}$, the more likely the braking converter $\mathrm{BC}$ switches on the braking resistor BR. Therefore, exceeding the overhead line voltage $U_{S T}$ and the related activation of the braking resistor $\mathrm{BR}$, is evidence of a lack of reception of the generated recuperation energy and can be used as indicators for assessing the degree of recouped energy utilization. The more often that voltage in the overhead lines is exceeded and the more often the braking resistors are switched on, the less energy is used for recuperation. In other words, the greater is the unused potential to increase the energy efficiency of the supply system.

As already indicated, the power supply system structure has a major impact on the degree of using recouped energy. To verify the influence of the spatial structure of the supply system on the use of recuperation in the Gdynia trolleybus service, utilization measurements of the use of recovery during braking were conducted.

The selection of indicators for assessing the degree of utilization of regenerative braking is important. To a large extent, it depends on the technical measurement capabilities. During the taking of these measurements, three indicators were selected as indicators of the recuperation's effectiveness:

- the effectiveness of recuperation in supply areas of individual substations, defined as the ratio of energy returned to the overhead lines and the total energy consumed; this indicator is determined based on measurements taken in the vehicles;

- the relative braking resistor switch-on time in vehicles in the areas of supply of individual substations; this indicator is determined based on measurements taken in the vehicles;

- the relative time of exceeding $770 \mathrm{~V}$ at the traction substations' busbars, which means a lack of consumers for the generated braking energy; this indicator was determined based on measurements taken at the traction substations.

The first factor determines the current level of utilization of recuperation. The second factor is a measure 
of the unused recuperation potential - switching of the braking resistor demonstrates a lack of acceptance for the generated energy and its loss, and thus provides insight on how to possibly improve energy efficiency. Similarly, the third factor provides insight on the existing potential to increase the efficiency of regenerative braking.

In 2011-2013, measurements were taken in the Gdynia supply system. The measurements were taken for traction substations and trolleys. For the purposes of measurement, an on-board system of registration of the energy consumed was used along with the recorded GPS positions over time. This allowed for the identification of precise energy consumption in each supply section.

During the measurements, the following quantities were noted, which enabled the determination of the value of recuperation effectiveness indicators:

- in traction substations:

- feeder voltages and currents;

- voltages of busbars in traction substations;

- in vehicles:

- voltage and current of the traction drive;

- voltage and current of auxiliary equipment;

- braking resistor switch-on time;

- voltage on the vehicle's current collector.

The results of the calculations are based on measurements taken between December 2011 and November 2012, with the winter period being the months of January to February, and the months of July to August as the summer period.

Figs 13-15 show a comparison of the relative time for exceeding $770 \mathrm{~V}$ at the substation busbars, the relative time of the braking resistor switch-on time and the efficiency of recuperation in the power supplies of the individual traction substations. The frequent occurrence of resistor braking is visible in the supply areas of the smallest substations, i.e. TS9 and TS7. Also notable is the significant difference between the time of resistive braking and days of the week, which results from the lower frequency of vehicle runs and the larger number of vehicles equipped with recuperation during Saturdays and Sundays. The effectiveness of regenerative braking (Fig. 15) is by far the smallest in substations TS7 and TS8. It should be noted that although the effectiveness of regenerative braking in the area of TS9 (Fig. 15) is relatively high, approximately $30 \%$, it frequently exceeds the overhead line voltage and frequently switches on the regenerative braking resistor (Figs 13-14). This demonstrates high potential opportunities (the mountainous nature of the route) for increasing the use of recuperation in the substation supply area.

The next stage of the research was to analyse the spatial characteristics of regenerative braking. For this purpose, the relative time of regenerative braking resistor switch-on time at different points of the overhead lines was analysed. The results of this analysis are shown in Figs 16-17 with maps of resistive braking intensity during summer and winter. The intensity of the colour and thickness of the line are dependent on the relative resistive braking switch-on time.

The first thing to pay attention to is the increased use of energy from regenerative braking (smaller rela-

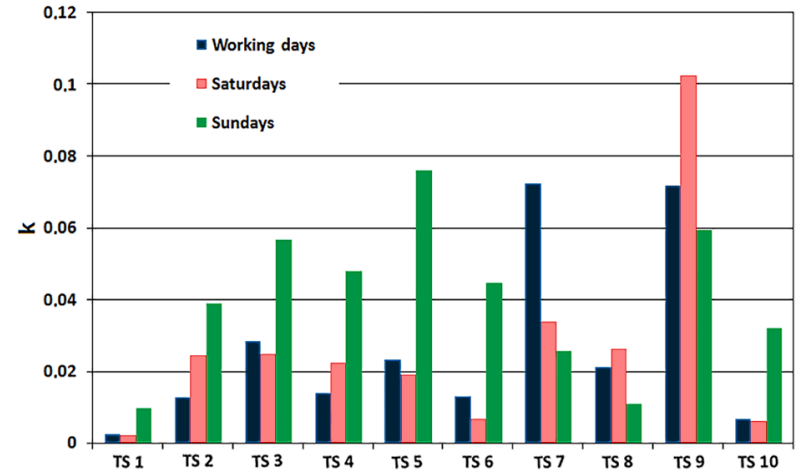

Fig. 13. Relative time of exceeding $770 \mathrm{~V}$ voltage of traction substations

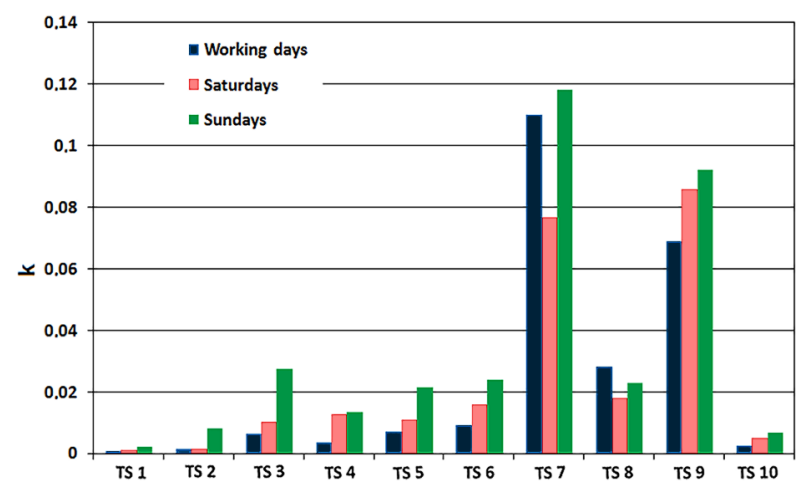

Fig. 14. Relative energy recovered by trolleybuses in supply areas of several substations

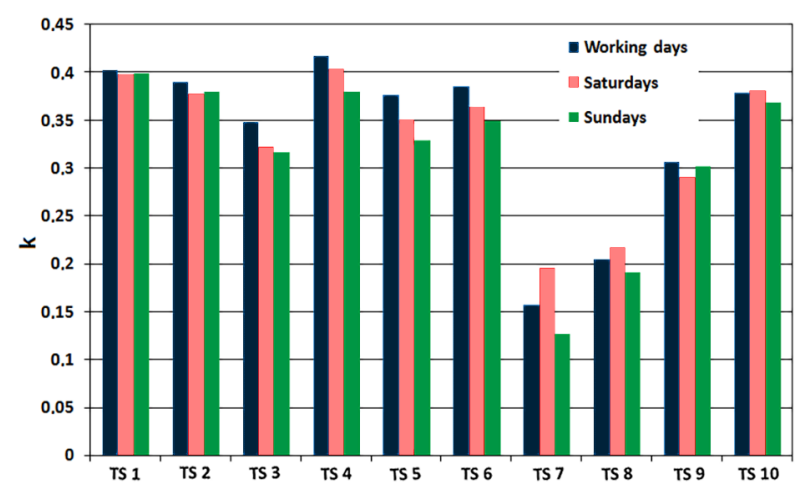

Fig. 15. Relative time of resistor breaking in supply areas of several substations

tive braking resistor switch-on time) in the summer and winter. This is the effect of higher energy consumption in the winter, which creates better conditions for the flow of regenerative braking energy at the vehicle-vehicle path. However, a key finding is the spatial differentiation of the nature of regenerative braking. Similarly to the previous part of this analysis, the poor use of energy recovery is clearly visible in the TS7, TS8 and TS9 substations. This is the result of low traffic in the supply areas of the listed substations and the mountainous nature of TS9. It should be noted, that resistive braking occurs in the western part of supply section $9 / 1$, which includes steep access. In the eastern, flat part, resistor braking is much less visible. 


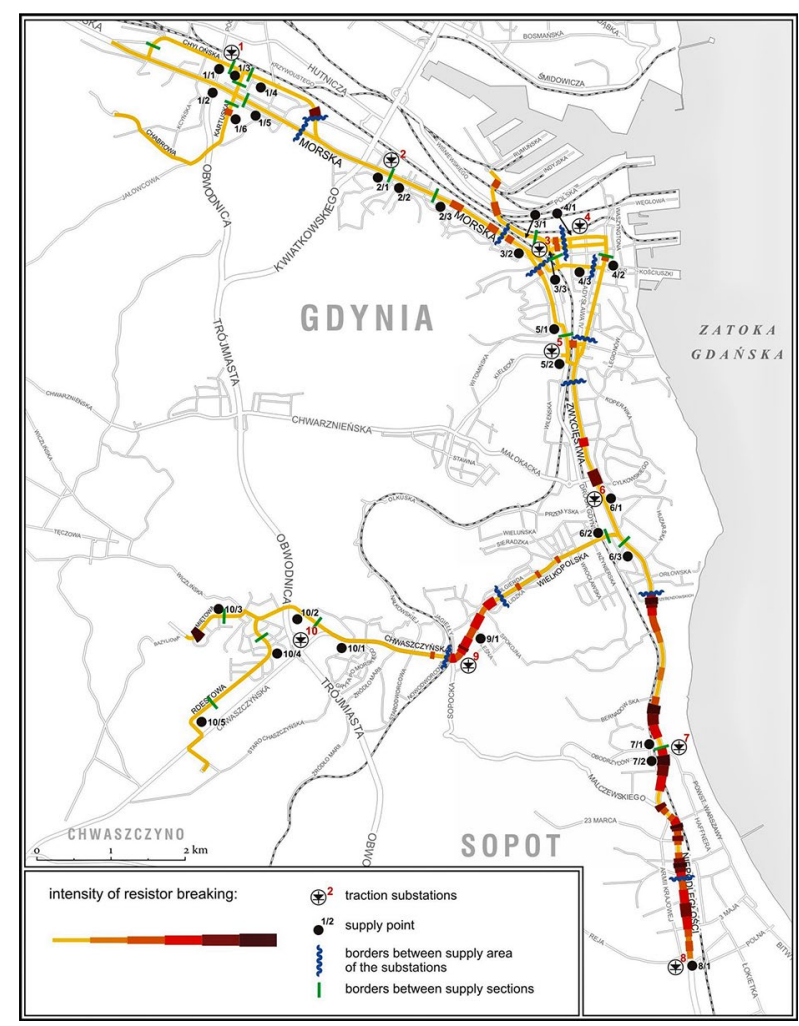

Fig. 16. Resistor braking intensity map - winter

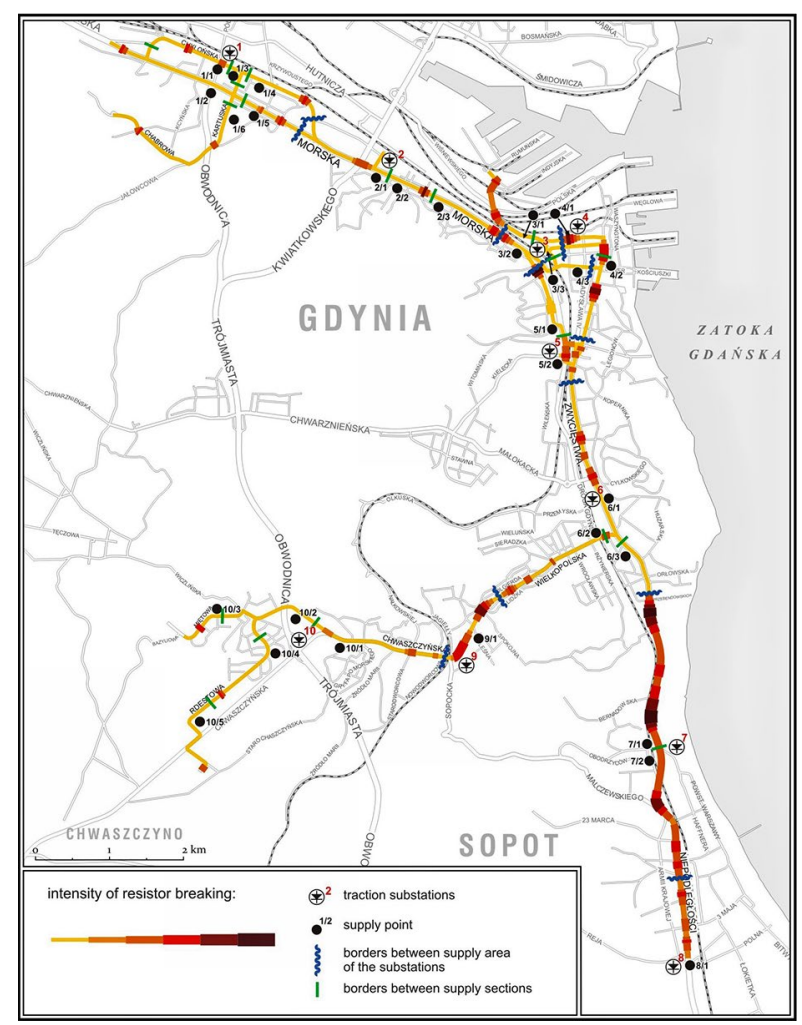

Fig. 17. Resistor braking intensity map - summer

For other substations, the areas where braking to the resistor occurs are much smaller, which indicates a much better use of energy recovery. An important observation is the significant relationship between the spatial nature of the resistor braking and the factors affecting road traffic. Less important, however, is the relationship between the spatial nature of resistor braking and the electric parameters of the supply area. The first relationship is expressed in the overlapping of areas in which the operation of the braking resistor is more common, with areas of heavy traffic, i.e. mainly crossroads. In Figs 16-17, the areas of frequent resistive braking are random and coincide with the location of major intersections in the city. This results in frequent braking in those areas, which results in a higher probability of braking to the resistor. During regenerative braking on the vehicle-vehicle path, the energy flows through the overhead lines. These lines have unit resistance, which provides resistance for electrical current flow and hinders the recovery of braking energy. Therefore, one would expect that with increasing distance from the supply point, the conditions for energy recovery are worse, and therefore, the areas of resistor braking are more visible. However, the conducted analysis does not confirm this hypothesis. For example, both in summer and winter, in the power supply section numbered $1 / 6$, the areas with the most frequent occurrence of resistor braking are located at the power supply point; moreover, this section is powered with a short feeder that is only 200 meters long. From the resistance of the power grid point of view, the conditions for receiving recouped energy should be the best. This indicates the small relative value of recuperation energy transmission losses. This argument emphasizes the importance of the use of braking energy in the vehicle-vehicle path and the need to increase it through the appropriate supply system structure.

\section{Conclusions}

The conducted analysis shows the importance of the spatial structure of the municipal transport overhead line's power supply system. This affects both transmission losses and the effective use of regenerative braking. In addition, the costs of construction and operation of the power supply system are dependent on the spatial aspects of the supply system.

The measurements taken and simulation conducted indicate a strong relationship between traffic conditions, the spatial structure of the supply system and the efficiency of the use of regenerative braking. A key element in determining the effective use of recuperation is the topology of the overhead lines. For supply areas with a significant number of vehicles, i.e. with high traffic volume or high intensity, the use of braking energy in the vehicle-vehicle path is very visible. Parts of the power supply system with low traffic intensity create poor conditions for the use of regenerative braking, which results in a frequent loss of energy in braking resistance. It should be noted that the braking energy flow in the vehicle-vehicle path is the cheapest and most effective way to use recuperation in vehicles - much cheaper than the use of banks or substation inverters.

Newly-built power supply systems should use a bilateral, decentralized overhead line power supply system. Such systems have the lowest energy transmission 
Table 3. The main measures related to reducing energy consumption in municipal transport by changing the spatial structure of the supply system

\begin{tabular}{ll}
\hline \multicolumn{1}{c}{ Designed power supply systems } & \multicolumn{1}{c}{ Existing supply systems } \\
\hline - introduction of a bilateral, decentralized power & - conduct of a measurement analysis of the recuperation utilization level; \\
supply system; & - introduction of bilateral power supply at the local level in central systems; \\
- avoiding too dense division of the overhead & - introduction of bilateral power supply in existing small-sized substations; \\
lines into the supply sections. & - introduction of a two-point power supply; \\
& - increasing the length of the supply system by combining several sections. \\
\hline
\end{tabular}

losses and high degree of utilization of energy recovery. In many cases, this degree is sufficient enough so that it is unnecessary to have additional recuperation energy storage equipment, e.g. supercapacitor banks. Under the current economic conditions, a decentralized system is also the cheapest in terms of both construction and operation. The use of central systems should be limited to areas where, due to dense development, there are significant problems with locating new substations.

With already-existing overhead power systems, it is recommended to measure the degree of utilization of recuperation and the level of voltage in the overhead lines, similar as was outlined in Chapter 7. This will allow for assessing the current state of the power supply system and become the basis for the possible reconstruction and eco-configuration of the supply system, which will facilitate the flow of energy from regenerative braking. This can be achieved by introducing a bilateral power supply system on a local scale, i.e. by combining the boundaries of adjacent sections supplied from different substations. For example, with the Gdynia trolleybus service (Figs 16-17), local bilateral supply should be introduced between sections $3 / 2$ and $2 / 3$. The adjacent boundaries of those sections present frequent switching of the braking resistor, which means the under-utilization of recovered energy. Bilateral power supply should also be introduced for small substations supplying small supply areas, which will both increase the use of recuperation and decrease losses in the supply system. This is particularly important in suburban lines, which are often powered by small traction substations. Low traffic intensity and a small number of hold-ups creates a low potential for energy recovery, the effect of which is the unprofitable use of supercapacitor banks. Bilateral power supply allows for an increase in recovery efficiency and improved supply conditions at a minimal cost.

In the Gdynia trolleybus service (Figs 16-17), it is advisable to implement bilateral power supply in the area of substations No. 7 and 8 , by joining sections $7 / 2-$ $8 / 1$ and $6 / 3-7 / 1$. Under the existing centralized power supply systems, it is also advisable to connect some adjacent power supply sections fed from a single substation, through which a two-point supply will thus be obtained. This will shorten the path of current flow by bypassing the feeders. Table 3 shows a summary of the main measures for the reduction of energy consumption in municipal transport by changing the spatial structure of the power supply system.

In areas with higher generation of regenerative braking energy, e.g. mountainous areas, it is advisable to use supercapacitor banks or substation inverters. However, as demonstrated by the studies, in the case of standard transport systems, the right power supply system structure can create conditions for the almost total use of recuperation energy. Many experts note the overestimation of the role of energy storage banks in reducing the energy intensity of electrified municipal transportation. Similar results can be obtained with much less financial investment by ensuring the appropriate spatial structure of the power supply system.

This study provides an important contribution to the issues of traction power engineering through the analysing the impact of the spatial structure of the overhead lines' power supply on the efficiency of urban electric traction. The study complements existing research in the energy consumption of rolling stock and public power systems.

This research was carried out for a trolleybus service; however, it is expected that the phenomena present in power supply systems of other rail vehicles, especially tram networks, would be similar. The proposed procedure is recommended for implementation in every city interested in increasing the efficiency of their electric transport.

\section{Acknowledgements}

This paper has been elaborated in the framework of the project Opportunity for young researchers, Reg. No. CZ.1.07/2.3.00/30.0016, supported by Operational Programme Education for Competitiveness and cofinanced by the European Social Fund and the state budget of the Czech Republic.

\section{References}

Barrero, R.; Van Mierlo, J.; Tackoen, X. 2008. Energy savings in public transport, IEEE Vehicular Technology Magazine 3(3): 26-36. http://dx.doi.org/10.1109/MVT.2008.927485

Brenna, M.; Falvo, M. C.; Foiadelli, F.; Martirano, L.; Poli, D. 2012a. Sustainable energy microsystem (SEM): preliminary energy analysis, in 2012 IEEE PES Innovative Smart Grid Technologies (ISGT), 16-20 January 2012, Washington, DC, 1-6. http://dx.doi.org/10.1109/ISGT.2012.6175735

Brenna, M.; Foiadelli, F.; Zaninelli, D. 2012b. Integration of recharging infrastructures for electric vehicles in urban transportation system, 2012 IEEE International Energy Conference and Exhibition (ENERGYCON), 9-12 September 2012, Florence, 1060-1064. http://dx.doi.org/10.1109/EnergyCon.2012.6347726

Destraz, B.; Barrade, P.; Rufer, A.; Klohr, M. 2007. Study and simulation of the energy balance of an urban transporta- 
tion network, in 2007 European Conference on Power Electronics and Applications, 2-5 September 2007, Aalborg, Denmark, 1-10.

http://dx.doi.org/10.1109/EPE.2007.4417349

Diez, A. E.; Diez, I. C.; Lopera, J. A.; Bohorquez, A.; Velandia, E.; Albarracin, A.; Restrepo, M. 2012. Trolleybuses in smart grids as effective strategy to reduce greenhouse emissions, in 2012 IEEE International Electric Vehicle Conference (IEVC), 4-8 March 2012, Greenville, SC, 1-6. http://dx.doi.org/10.1109/IEVC.2012.6183213

Dolecek, R.; Cerny, O.; Novak, J.; Bartłomiejczyk, M. 2012. Interference in power system for traction drive with PMSM, Przeglad Elektrotechniczny - Electrical Review (9a): 204-207.

Donno, M.; Ferrari, A.; Scarpelli, A.; Perlo, P.; Bocca, A. 2012. Mechatronic system for energy efficiency in bus transport, in 2012 Design, Automation \& Test in Europe Conference \& Exhibition (DATE), 12-16 March 2012, Dresden, Germany, 342-343. http://dx.doi.org/10.1109/DATE.2012.6176493

Falvo, M. C.; Foiadelli, F. 2010. Preliminary analysis for the design of an energy-efficient and environmental sustainable integrated mobility system, in 2010 IEEE Power and Energy Society General Meeting, 25-29 July 2010, Minneapolis, MN, 1-7. http://dx.doi.org/10.1109/PES.2010.5589545

Falvo, M. C.; Lamedica, R.; Bartoni, R.; Maranzano, G. 2011. Energy management in metro-transit systems: an innovative proposal toward an integrated and sustainable urban mobility system including plug-in electric vehicles, Electric Power Systems Research 81(12): 2127-2138. http://dx.doi.org/10.1016/j.epsr.2011.08.004

Foiadelli, F; Roscia, M.; Zaninelli, D. 2006. Optimization of storage devices for regenerative braking energy in subway systems, in 2006 IEEE Power Engineering Society General Meeting, 18-22 June 2006, Montreal, Canada. http://dx.doi.org/10.1109/PES.2006.1708894

García, P.; Torreglosa, J. P.; Fernández, L. M.; Jurado F. 2013. Control strategies for high-power electric vehicles powered by hydrogen fuel cell, battery and supercapacitor, Expert Systems with Applications 40(12): 4791-4804. http://dx.doi.org/10.1016/j.eswa.2013.02.028

Gerndt, H.; Stellmacher, R. 1989. Battery powered electric buses, Transportation Planning and Technology 14(3): 217-225. http://dx.doi.org/10.1080/03081068908717427

Gunselmann, W. 2005. Technologies for increased energy efficiency in railway systems, in 2005 European Conference on Power Electronics and Applications, 11-14 September 2005, Dresden, Germany, 1-10. http://dx.doi.org/10.1109/EPE.2005.219712

Hamacek, S.; Bartłomiejczyk, M.; Hrbáč, R.; Mišák, S.; Stýskala, V. 2014. Energy recovery effectiveness in trolleybus transport, Electric Power Systems Research 112: 1-11. http://dx.doi.org/10.1016/j.epsr.2014.03.001

Hrbáč, R.; Mlčák, T.; Kolář, V.; Nečas, J. 2014. Estimation of on-fly phase resistance of on $8 / 6$ switched reluctance motor for sensorless control, Elektronika ir Elektrotechnika 20(5): 15-20. http://dx.doi.org/10.5755/j01.eee.20.5.7093

Hrbáč, R.; Mlčák, T.; Kolář, V.; Nečas, J.; Rusnok, S. 2013. Phase winding resistance estimation during operation of the switched reluctance motor, in The 7th International Scientific Symposium “Elektroenergetika 2013", 18-20 September 2013, Stará Lesná, Slovakia, 521-524.

Iannuzzi, D.; Ciccarelli, F.; Lauria, D. 2012. Stationary ultracapacitors storage device for improving energy saving and voltage profile of light transportation networks, Transportation Research Part C: Emerging Technologies 21(1): 321-337. http://dx.doi.org/10.1016/j.trc.2011.11.002
Jarzebowicz, L. 2014. Indirect measurement of motor current derivatives in PMSM sensorless drives, Elektronika ir Elektrotechnika 20(7): 23-26.

http://dx.doi.org/10.5755/j01.eee.20.7.8019

Jarzebowicz, L. 2011. Sensorless IPMSM drive with rotor position estimator based on analysis of phase current derivatives, in 2011 IEEE International Symposium on Industrial Electronics (ISIE), 27-30 June 2011, Gdansk, Poland, 733738. http://dx.doi.org/10.1109/ISIE.2011.5984248

Kühne, R. 2010. Electric buses: an energy efficient urban transportation means, Energy 35(12): 4510-4513.

Pohl, J. 2014. Elektrobusy pro městská centra, in Odborná konference „Elektrické autobusy pro mèsto III“, 21. listopadu 2014, Praha, Česká republika (in Czech).

Połom, M.; Bartłomiejczyk, M. 2011. Trolleybusses in the city of Gdynia. A historical and geographical study, in M. Bartłomiejczyk, M. Połom (Eds.). Determinants of Functioning of Trolleybus Transport in Selected Cities of the European Union, 119-139.

Połom, M.; Palmowski, T. 2009. Rozwój i funkcjonowanie komunikacji trolejbusowej w Gdyni. Pelplin: Wydawnictwo Bernardinum. 152 p. (in Polish).

Scarpellini, S.; Valero, A.; Llera, E.; Aranda, A. 2013. Multicriteria analysis for the assessment of energy innovations in the transport sector, Energy 57: 160-168. http://dx.doi.org/10.1016/j.energy.2012.12.004

Skibicki, J.; Judek, S. 2009. Wyznaczanie parametrów elektrycznych trakcyjnego układu zasilania dla złożonych warunków ruchu przy wykorzystaniu programu PSpice [Evaluation of traction supply system electrical parameters for complex traffic condition using PSpice simulation program], Przegląd Elektrotechniczny - Electrical Review (12): 270-273. (in Polish).

Sweeting, W. J.; Hutchinson, A. R.; Savage, S. D. 2011. Factors affecting electric vehicle energy consumption, International Journal of Sustainable Engineering 4(3): 192-201. http://dx.doi.org/10.1080/19397038.2011.592956

White, P. 1982. Energy conservation in urban public transport, Transportation Planning and Technology 7(3): 143-152. http://dx.doi.org/10.1080/03081068208717217 